\title{
PEMODELAN DAN PERAMALAN DATA DERET WAKTU DENGAN METODE SEASONAL ARIMA
}

\author{
ANNISA UL UKHRA \\ Program Studi Matematika, \\ Fakultas Matematika dan Ilmu Pengetahuan Alam, Universitas Andalas, \\ Kampus UNAND Limau Manis Padang, Indonesia, \\ annisaulukhra25@gmail.com
}

\begin{abstract}
Abstrak. Penelitian ini mempelajari suatu metode dalam meramalkan data time series yang berupa data musiman. Metode yang dipakai dalam penelitian ini adalah Seasonal Autoregressive Integrated Moving Average (SARIMA). Metode ini merupakan gabungan dari proses Autoregressive ( $A R$ ) Musiman dan Moving Average (MA) Musiman. Metode ini diaplikasikan pada data jumlah penumpang suatu maskapai penerbangan dari tahun 1949 - 1959. Sehingga diperoleh ramalan jumlah penumpang untuk tahun berikutnya. Hasil tersebut dibandingkan dengan data aktual dimana data yang diperoleh tidak jauh berbeda dengan data aktual.
\end{abstract}

Kata Kunci: Metode SARIMA, AR Musiman, MA Musiman

\section{Pendahuluan}

Analisis deret waktu pada dasarnya digunakan untuk melakukan analisis data yang mempertimbangkan pengaruh waktu. Data dikumpulkan secara periodik berdasarkan urutan waktu, bisa dalam jam, hari, minggu, bulan, kuartal dan tahun. Analisis deret waktu dapat dilakukan untuk membantu dalam menyusun perencanaan ke depan. Sebagai contoh, dalam kasus peramalan banyaknya penumpang suatu maskapai penerbangan dalam rentang waktu tertentu, yang diperlukan hanya data jumlah penumpang pada tahun-tahun sebelumnya. Model deterministik adalah model yang nilai observasi mendatang dapat dihitung atau dapat diramalkan secara pasti melalui suatu fungsi berdasarkan observasi masa lampau, tetapi peramalan hanya berlaku untuk data yang ada saja. Untuk menentukan metode peramalan pada data deret waktu perlu diketahui pola dari data tersebut sehingga peramalan data dapat dilakukan dengan metode yang sesuai. Pola data dapat dibedakan menjadi empat jenis, yaitu pola musiman, siklis, trend, dan irregular [5]. Pola musiman merupakan fluktuasi dari data yang terjadi secara periodik dalam kurun waktu satu tahun, seperti triwulan, kuartalan, bulanan, mingguan, atau harian. Pola siklis terjadi apabila datanya dipengaruhi oleh fluktuasi ekonomi jangka panjang, seperti yang berhubungan dengan siklus bisnis. Pola ini sulit dideteksi dan tidak dapat dipisahkan dari pola trend. Pola trend merupakan kecenderungan arah data dalam jangka panjang, dapat berupa kenaikan maupun penurunan. Sedangkan pola irregular merupakan kejadian yang tidak terduga dan bersifat acak, tetapi kemunculannya dapat mempengaruhi fluktuasi data time series. 
Untuk data model stokastik terdapat beberapa model yang dapat digunakan seperti $A R, M A, A R M A, A R M A, S A R I M A$ dan lainnya. Jika data mempunyai pola musiman, maka metode yang lebih tepat adalah Seasonal Autoregressive Integreted Moving Average(SARIMA). Metode inilah yang menjadi pokok bahasan pada paper ini.

\section{Metodologi}

Langkah-langkah pemodelan Seasonal Autoregressive Integrated Moving Average(SARIMA) adalah:

(1) Proses identifikasi model.

(2) Pendugaan parameter model.

(3) Pemeriksaan residual(sisaan).

(4) Mengunakan model untuk peramalan jika model memenuhi syarat.

\section{Model Autoregressive Integrated Moving Average (ARIMA)}

\subsection{Model Autoregressive (AR)}

Model $A R(p)$ adalah model dimana $X_{t}$ merupakan fungsi dari data di masa yang lalu, yakni $t-1, t-2, \cdots, t-p$. Persamaan AR diberikan oleh

$$
X_{t}=\mu+\phi_{1} X_{t-1}+\phi_{2} X_{t-2}+\cdots+\phi_{p} X_{t-p}+e_{t},
$$

\subsection{Model Moving Average (MA)}

Model $M A(q)$ adalah model untuk memprediksi $X_{t}$ sebagai fungsi dari kesalahan prediksi di masa lalu (past forecast error) dalam memprediksi $X_{t}$. Persamaan $M A$ diberikan oleh:

$$
X_{t}=\mu+e_{t}-\theta_{1} e_{t-1}-\theta_{2} e_{t-2}-\cdots-\theta_{q} e_{t-q}
$$

\subsection{Model ARIMA}

Model ARIMA dilakukan pada data stasioner atau data yang didifferencing sehingga data telah stasioner. Secara umum, model $A R I M A$ dinotasikan sebagai $A R I M A(p, d, q)$. Model ini merupakan gabungan dari model $A R M A(p, q)$ dan proses differencing, yaitu

$$
\phi_{p}(B)(1-B)^{d} X_{t}=\theta_{0}+\theta_{q}(B) e_{t}
$$

\section{Metode Seasonal Autoregressive Integrated Moving Average (SARIMA)}

\subsection{Proses Moving Average(MA) Musiman}

Bentuk umum dari proses Moving Average musiman periode $S$ tingkat $Q$ atau $M A(Q)^{S}$ didefinisikan sebagai berikut.

$$
X_{t}=e_{t}-\Theta_{1} e_{t-S}-\Theta_{2} e_{t-2 S}-\cdots-\Theta_{Q} e_{t-Q S},
$$


dimana $e_{t}$ bersifat saling bebas terhadap $X_{t-1}, X_{t-2}, \cdots$ yang berdistribusi normal dengan mean 0 dan varian $\sigma^{2}$.

Sebagai contoh dari model $M A(Q)^{S}$ akan dijelaskan dalam model $M A(1)^{12}$. Suatu proses $X_{t}$ dikatakan mengikuti $M A(1)^{12}$ jika $X_{t}$ mengikuti model

$$
X_{t}=e_{t}-\Theta_{1} e_{t-12} .
$$

\subsection{Proses Autoregressive(AR) Musiman}

Bentuk umum dari proses Autoregressive musiman periode $S$ tingkat $P$ atau $A R(P)^{S}$ didefinisikan sebagai

$$
X_{t}=\Phi_{1} X_{t-S}+\Phi_{2} X_{t-2 S}+\cdots+\Phi_{P} X_{t-P S}+e_{t} .
$$

dimana $e_{t}$ bersifat saling bebas $X_{t-1}, X_{t-2}, \cdots$ yang berdistribusi normal dengan mean 0 dan varian $\sigma^{2}$.

Sebagai contoh dari model $A R(P)^{S}$ akan dijelaskan dalam model $A R(1)^{12}$. Suatu proses $X_{t}$ dikatakan mengikuti $A R(1)^{12}$ jika $X_{t}$ mengikuti model

$$
X_{t}=\Phi_{1} X_{t-12}+e_{t} .
$$

\subsection{Model Seasonal ARIMA}

Musiman adalah kecenderungan mengulangi pola tingkah gerak dalam periode musim, biasanya satu tahun untuk data bulanan. Model ARIMA Musiman merupakan model ARIMA yang digunakan untuk menyelesaikan time series musiman yang terdiri dari dua bagian, yaitu bagian tidak musiman (non-musiman) dan bagian musiman. Bagian non-musiman dari metode ini adalah model ARIMA.

Secara umum bentuk model ARIMA musiman atau ARIMA $(p, d, q)(P, Q, S)^{S}$ adalah:

$$
\phi_{p}(B) \Phi_{P}\left(B^{S}\right)(1-B)^{d}\left(1-B^{S}\right)^{D} X_{t}=\theta_{q}(B) \Theta_{Q}\left(B^{S}\right) e_{t},
$$

\section{Peramalan Data Deret Waktu Musiman dengan Menggunakan Metode Seasonal Autoregressive Integreted Moving Average (SARIMA)}

Data yang digunakan dalam penerapan metode ini adalah data AirPassengers (dalam ribuan) perbulan dari suatu maskapai penerbangan pada periode 1949 1959. Langkah pertama yang dilakukan adalah proses identifikasi model. Proses identifikasi model pertama kali diuji apakah data stasioner atau tidak yaitu dengan melihat plot data asli serta ACF dan PACF dari data asli. Time series plot untuk data tersebut adalah:

Gambar 1 memperlihatkan bahwa data dipengaruhi pola trend sekaligus pola musiman karena plot menunjukkan fluktuasi meningkat, yaitu gerakan dari kiri bawah ke kanan atas pada grafik dan berulang pada bulan tertentu Gambar 1 memperlihatkan bahwa pola musiman lebih kuat daripada pola trend sehingga pola trend tampak tidak begitu jelas. Gambar 2 dan Gambar 3 memperlihatkan terjadi autokorelasi pada data, yaitu adanya bar yang yang melebihi garis putus-putus 


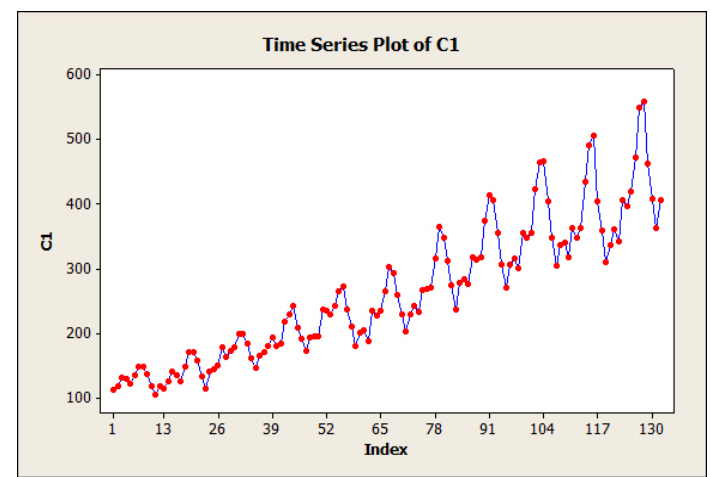

Gambar 1. Time Series dan AirPassengers

sehingga data tidak stasioner. Oleh karena itu, data AirPassengers perlu dilakukan differencing untuk menstasionerkan data tersebut.

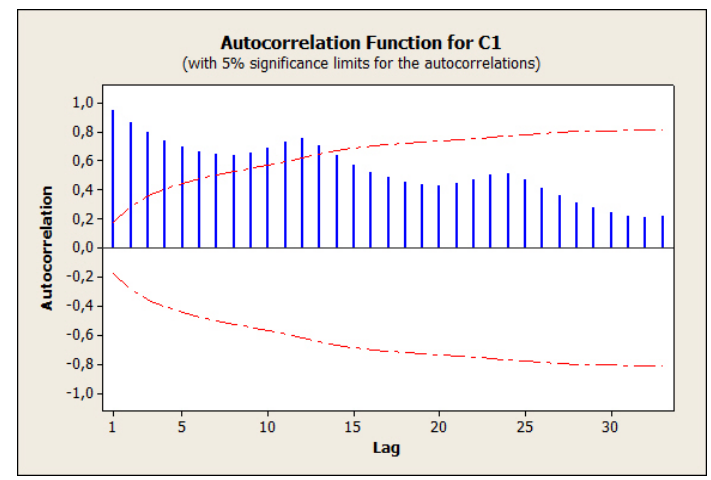

Gambar 2. Grafik ACF AirPassengers

Gambar 4 merupakan plot data AirPassengers setelah data dilakukan differencing pertama dan musiman lag 12. Dari plot tersebut terlihat bahwa data telah stasioner dalam rata-rata dan varians setelah differencing pertama dan musiman lag 12 karena fluktuasi datanya horizontal sepanjang sumbu waktu dan berarti nilai $d=1, D=12$.

Setelah dilakukan differencing pertama dan musiman lag 12, tahap selanjutnya adalah pendugaan parameter model dengan menggunakan cara mencoba-coba (trial and error) yaitu menguji beberapa nilai yang berbeda. Pendugaan parameter dapat dilakukan dengan melihat grafik $A C F$ dan $P A C F$ data setelah dilakukan differencing pertama dan musiman lag 12. Gambar 5 dan Gambar 6 berikut merupakan grafik dari $A C F$ dan $P A C F$ setelah dilakukan differencing pertama dan musiman lag 12 .

Dari Gambar 5 dan Gambar 6 akan didapat beberapa kandidat model SARIMA 


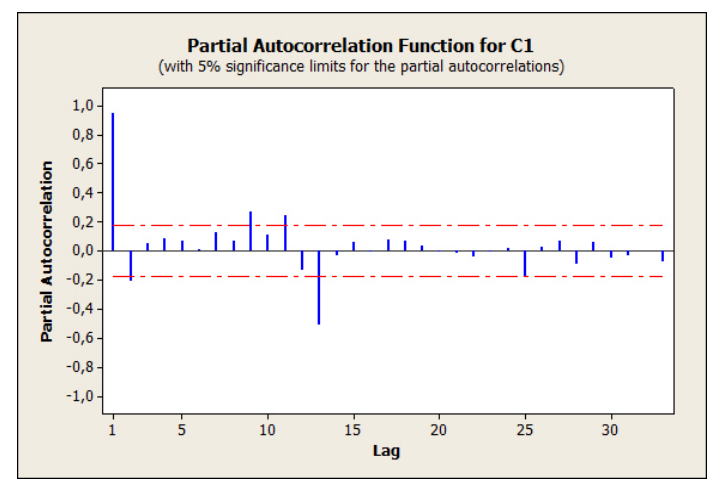

Gambar 3. Grafik PACF AirPassengers

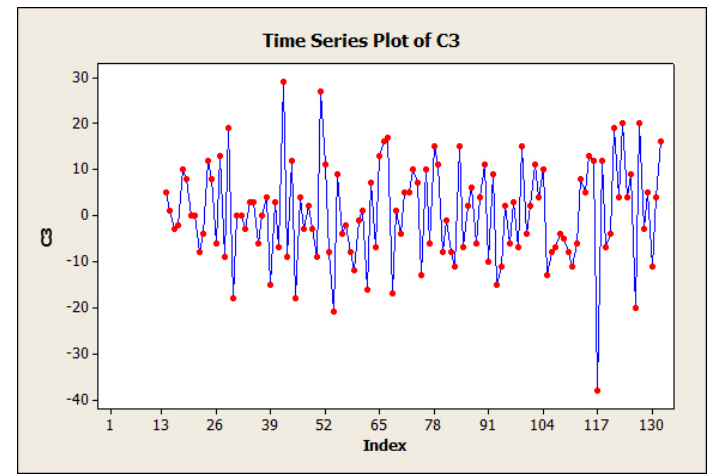

Gambar 4. Plot data AirPassengers setelah dilakukan differencing pertama dan musiman lag 12

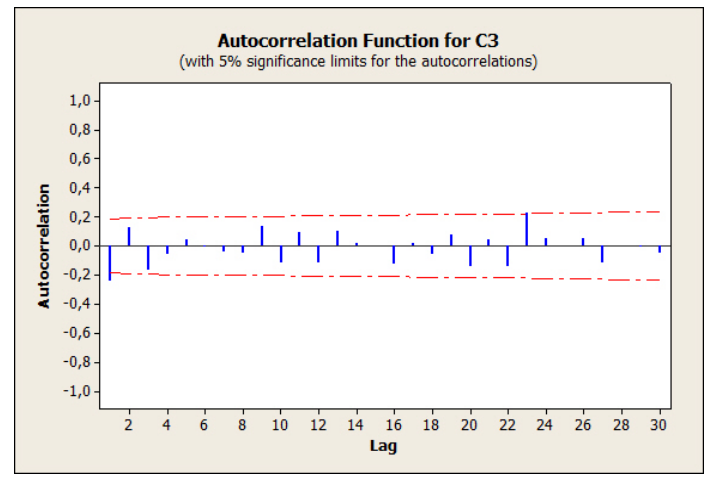

Gambar 5. Grafik ACF AirPassangers setelah dilakukan differencing pertama dan musiman lag 12 


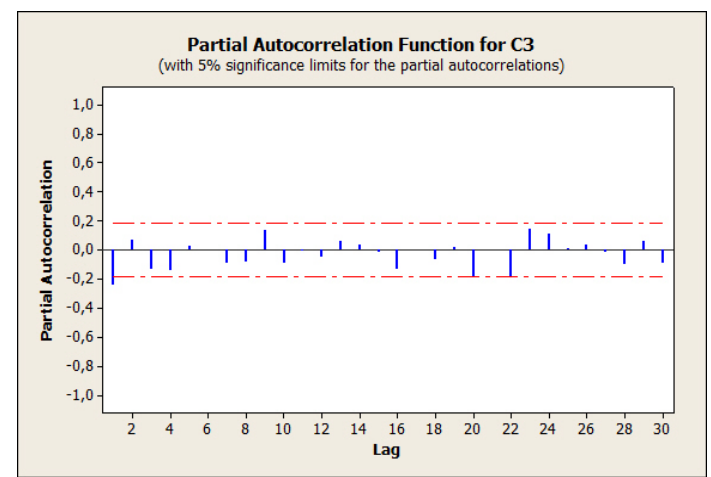

Gambar 6. Grafik PACF AirPassangers setelah dilakukan differencing pertama dan musiman lag 12

dengan melihat bar yang melebiihi garis putus-putus. Pada grafik $A C F$ terlihat bahwa pada bar pertama garis vertikal melewati garis putus-putus begitu juga dengan grafik $P A C F$ pada bar pertama garis vertikal juga melewati garis putus-putus. Dengan demikian diperoleh beberapa kandidat model SARIMA data AirPassengers yang diperlihatkan pada Tabel 1 .

Tabel 1. Kandidat Model SARIMA Data AirPassengers dengan Metode Seasonal ARIMA

\begin{tabular}{|c|c|c|}
\hline Model & MSE & Keterangan \\
\hline ARIMA $(1,1,1)(0,1,0)^{12}$ & 110.4 & $\begin{array}{c}\mathrm{AR}(1) \text { dan MA(1) } \\
\text { signifikan }\end{array}$ \\
\hline ARIMA $A(1,1,0)(0,1,0)^{12}$ & 110.3 & $\mathrm{AR}(1)$ siginifikan \\
\hline ARIMA(0,1,1)(0,1,0) & 111.0 & $\mathrm{MA}(1)$ siginifikan \\
\hline
\end{tabular}

Dari tabel di atas dapat disimpulkan bahwa model $S A R I M A$ yang tebaik untuk data AirPassangers adalah $\operatorname{ARIMA}(1,1,0)(0,1,0)^{12}$ karena memiliki nilai MSD terkecil yaitu 110.3. Berdasarkan Gambar 7 AR(1) signifikan karena mempunyai nilai $p<0.05$. Hal ini menunjukkan bahwa model dapat digunakan.

Jadi model Seasonal ARIMA untuk data AirPassengers adalah

$$
\left[1-(-0.2473 B)(1-B)\left(1-B^{12}\right)\right] X_{t}=e_{t},
$$

dengan model peramalannya adalah

$$
\begin{aligned}
e_{t} & =(1-(-0.2473 B))(1-B)\left(1-B^{12}\right) X_{t} \\
& =(1+0.2473 B)\left(1-B^{12}-B+B^{13}\right) X_{t} \\
& =\left(1-B^{12}-B+B^{13}+0.2473 B-0.2473 B^{13}-0.2473 B^{2}+0.2473 B^{14}\right) X_{t} \\
& =\left(1-0.7527 B-0.2473 B^{2}-B^{12}+0.7527 B^{13}+0.2473 B^{14}\right) X_{t} .
\end{aligned}
$$




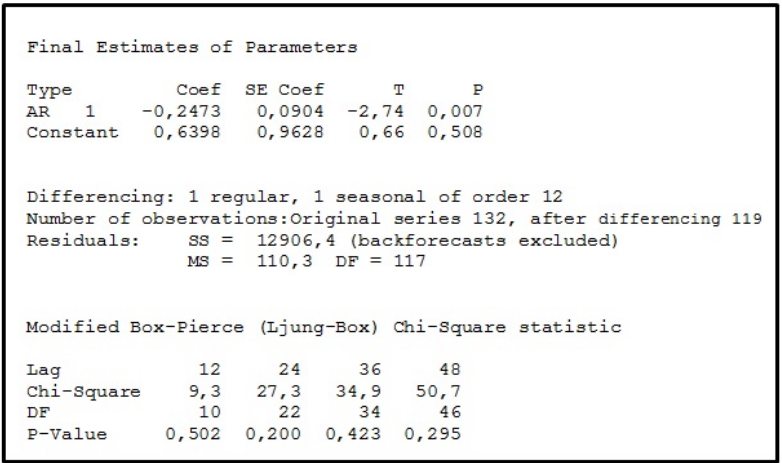

Gambar 7. Hasil analisis data PACF AirPassangers dengan metode Seasonal ARIMA

Jadi

$X_{t}=0.7527 X_{t-1}+0.2473 X_{t-2}+X_{t-12}-0.7527 X_{t-13}-0.2473 X_{t-14}+e_{t}$.

Selanjutnya dilakukan proses diagnostik untuk melihat tingkat kesalahan model, yaitu dengan melihat kenormalan distribusi residunya.

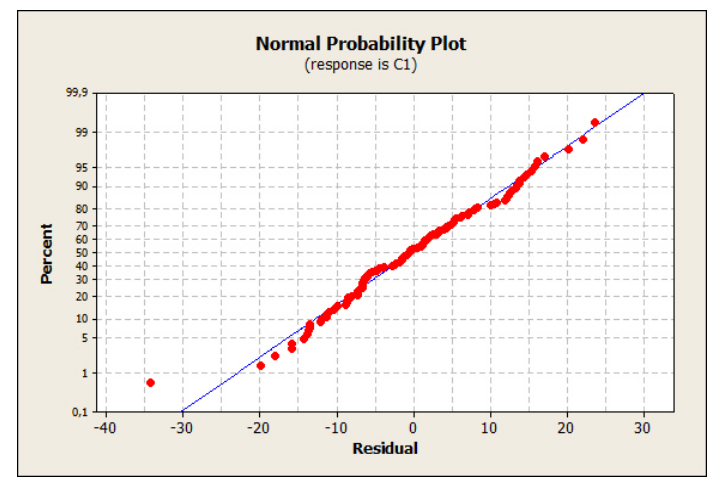

Gambar 8. Grafik Normal Probability Plot residu dari data PACF AirPassengers

Gambar 8 memperlihatkan residu mengikuti garis diagonal, yang berarti residu berdistribusi normal. Karena residu bersifat random dan berdistribusi normal, maka residu memenuhi asumsi white noise. Dari persamaan (4.2.1) didapatkan hasil peramalan data AirPassengers untuk tahun 1960 yang diberikan pada Tabel 2.

Gambar 9 dan Gambar 10 berikut memperlihatkan grafik perbadingan data hasil peramalan dengan data asli dan plot dari hasil peramalan untuk tahun 1960.

Pada Gambar 9 terlihat bahwa grafik data peramalan dengan data aktual sangat berdekatan. Yang berati bahwa hasil data peramalan hampir mendekati data aktual. Sedangkan pada Gambar 10 jika data hasil peramalan digabungkan dengan data sebelumnnya terlihat bahwa plot data hasil peramalan mengikuti pola dari data sebelumnya. 
Tabel 2. Hasil Peramalan Data AirPassengers dengan Metode Seasonal ARIMA Tahun 1960

\begin{tabular}{|c|c|c|}
\hline Bulan & Ramalan & Aktual \\
\hline Januari & 424.04 & 413 \\
\hline Februari & 401.72 & 391 \\
\hline Maret & 456.98 & 419 \\
\hline April & 417.9 & 461 \\
\hline Mei & 472.14 & 472 \\
\hline Juni & 527.21 & 535 \\
\hline Juli & 608.28 & 622 \\
\hline Agustus & 630.24 & 606 \\
\hline September & 516.68 & 508 \\
\hline Oktober & 452.49 & 461 \\
\hline November & 413.77 & 380 \\
\hline Desember & 431.9 & 432 \\
\hline
\end{tabular}

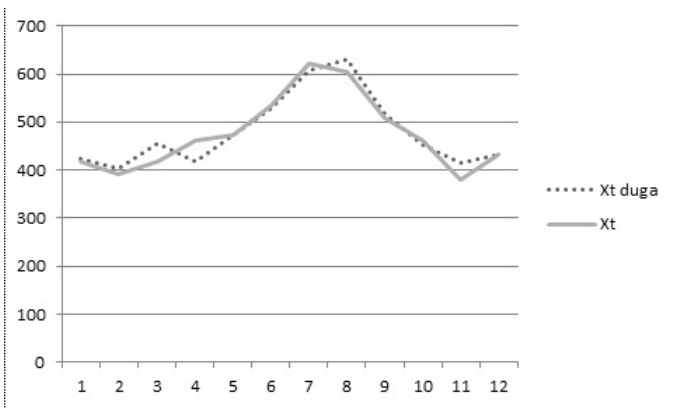

Gambar 9. Grafik Perbandingan Data Hasil Peramalan dengan Data Asli

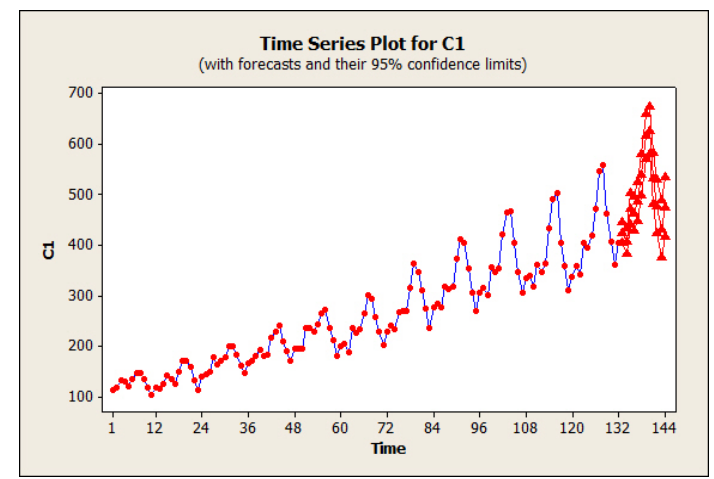

Gambar 10. Plot Hasil Peramalan data PACF AirPassengers Tahun 1960

\section{Kesimpulan}

Dari penjelasan diatas dapat diambil kesimpulan bahwa metode SARIMA dapat dipakai untuk data yang bersifat musiman yang dapat memberikan hasil peramalan 
yang tidak jauh berbeda dengan data aktual.

\section{Ucapan Terima kasih}

Penulis mengucapkan terima kasih kepada Ibu Dr. Maiyastri, Bapak Dr. Mahdhivan Syafwan, Ibu Hazmira Yozza, M.Si, Ibu Izzati Rahmi HG, M.Si, Ibu Dr. Lyra Yulianti, dan ibu Dr. Ferra Yanuar yang telah memberikan masukan dan saran sehingga paper ini dapat diselesaikan dengan baik.

\section{Daftar Pustaka}

[1] Box, G.E.P., Jenkins, G.M. and Reinsel, G.C. (1994). Time Series Analysis: Forecasting and Control Third Edition. New Jersey: Pearson Prentice Hall

[2] Brockwell, P.J and Davis, R.A., 1996, Introduction to Time Series and Forecasting. Spinger-Verlag New York

[3] Chatfield, C. (2000). Time-Series Forecasting. Boca Raton: Chapman and Hall/CRC

[4] Cryer, J.D,. 1986. Time Series Analysis. Duxbury Press, Boston.

[5] Hanke, J.E. and Wichern, D.W. (2005). Business Forecasting Eight Edition. New Jersey: Pearson Prentice Hall

[6] Makridakis, S., Wheelwright, S.C. and McGee, V.E. (1999). Metode dan Aplikasi Peramalan Jilid 1 (Ir. Untung Sus Ardiyanto, M.Sc. dan Ir. Abdul Basith, M.Sc. Terjemahan). Edisi Kedua. Jakarta: Penerbit Erlangga 